This is a PDF file of an unedited manuscript that has been accepted for publication in Energy Policy.

The manuscript will undergo copyediting, typesetting, and review of the resulting proof before it is published in its final form. Please note that during the production process errors may be discovered which could affect the content, and all legal disclaimers that apply to the journal pertain. The final version will be available at:

https://doi.org/10.1016/j.enpol.2013.06.133

\title{
A Multi-Objective Approach for Developing National Energy Efficiency Plans
}

\author{
Gustavo Haydt ${ }^{\text {a, }}{ }^{\text {Vítor Leal }}{ }^{\mathrm{b}}$ Luís Dias ${ }^{\mathrm{c}}$ \\ ${ }^{a}$ IE-UFRJ (Instituto de Economia, Universidade Federal do Rio de Janeiro), Av. Pasteur, no 250,Urca, 22290-240 Rio de Janeiro, RJ, Brazil \\ ${ }^{b}$ IDMEC - Instituto de Engenharia Mecânica, Faculdade de Engenharia, Universidade do Porto, Rua Dr. Roberto Frias, s.n., 4200-465 Porto, Portugal \\ ${ }^{c}$ INESC Coimbra / Faculdade de Economia, Universidade de Coimbra, Av Dias da Silva 165, 3004-512 Coimbra, Portugal
}

\begin{abstract}
This paper proposes a new approach to deal with the problem of building national energy efficiency (EE) plans, considering multiple objectives instead of just energy savings. The objectives considered are minimizing the influence of energy use on climate change, minimizing the financial risk from the investment, maximizing the security of energy supply, minimizing investment costs, minimizing the impacts of building new power plants and transmission infrastructures, and maximizing the local air quality. These were identified through literature review and interaction with real decision makers. A database of measures is established, from which millions of potential EE plans can be built by combining measures and their respective degree of implementation. Finally, a hybrid multi-objective and multi-criteria decision analysis (MCDA) model is proposed to search and select the EE plans that best match the decision makers' preferences. An illustration of the working mode and the type of results obtained from this novel hybrid model is provided through an application to Portugal. For each of five decision perspectives a wide range of potential best plans were identified. These wide ranges show the relevance of introducing multi-objective analysis in a comprehensive search space as a tool to inform decisions about national EE plans.
\end{abstract}

Keywords: energy efficiency, energy planning, multi-criteria analysis

\section{Introduction}

Energy related policies worldwide have been evolving towards strategies in which security of energy supply, environmental sustainability and economic competitiveness are the main concerns. In this context, policies to promote energy efficiency (EE) play a key role to contribute to these three main goals (IPCC, 2008; McKinsey \& Company, 2009). The EU Green Paper on energy efficiency (European Union et al., 2005) sustains that a consistent way to put in place EE initiatives is through policy instruments, with special attention to EE plans.

EE plans can be organized in several different ways, generally having some sort of energy savings targets set ahead. Some countries, such as the USA (U.S. Department of Energy and U.S. Environmental Protection Agency, 2006) and Brazil (Ministério de Minas e Energia, 2011) organized their EE plans as guidelines that can be used to improve EE in a country. Other countries,

* Corresponding author, e-mail:gustavo.haydt@ie.ufrj.br Tel:+55 21 38735269;fax:+55 2125418148 
such as those belonging to the European Union, were more concrete in the formulation of their plans, having to put together a list of $\mathrm{EE}$ measures, the expected quantitative results from such measures, and the expected total final energy savings, with a minimum target of $9 \%$ of the inland final energy use to be reached in a nine years period (European Parliament, 2006).

For the scope of this work, EE plans are defined as combinations of EE measures along with the respective degree of implementation of each measure. Each measure represents a change designed to decrease the overall energy use of a system to provide a specific service. EE measures may conserve energy through the replacement or renovation of systems and equipment (e.g., changing a boiler for a more efficient one) or through changing the management and operation of systems and the behavior of people (e.g., adjusting the lighting according to daylight).

To make sure that EE measures are made operational and work as planned, it is necessary to put in place promotion mechanisms and/or implementation processes. Such processes establish how to encourage, or even force, the society to accept and deploy EE. Typical implementation mechanisms are pricing policy and mandatory minimum efficiency standards. The measures can generally be implemented via different mechanisms, and such mechanisms rely on contextual variables and volatile political issues and interests. This diversity of the implementation mechanisms that can be applied for each physical/technical measure makes the problem of building EE plans even more complex than the already intricate problem of selecting the technical EE measures to be part of a plan. Therefore, it may be advisable to break the problem into two stages: first "the selection of physical/technical measures" and then "the selection of implementation mechanisms". In practice some iteration between the two stages may be needed, as the lack of a good implementation mechanism may hinder the adoption of a technically good measure, but it is believed that significant added clarity and other benefits may result from this decoupling. This work deals specifically with the first stage: selecting or identifying a set of good EE measures.

Since EE plans are characterized by technical EE measures, this raises the question of what would be the most appropriate selection of measures to include in an EE plan for a country. It is crucial to start by clarifying what "most appropriate" may actually mean. The most obvious answer would be based on the fact that EE aims at achieving energy savings; therefore, "most appropriate" would mean "with higher energy savings". However, energy savings affect a nation in several different ways, such as benefiting the national economy (becoming less energy dependent and more competitive), and improving the environment by reducing pollution associated with electricity generation and energy use. These indirect outcomes from energy savings are, probably, more important objectives than "saving energy" by itself. According to the Energy End-use Efficiency and Energy Services Directive (ESD) (European Parliament, 2006), "saving energy" is a means to achieve the implicit objectives of mitigating greenhouse gas emissions and increasing the security of energy supply. Keeney refers to this issue as the differentiation between "means objectives", those that are established or pursued in order to actually achieve another objective, and "ends objectives", the real objectives intended to be achieved (Keeney, 1996). Therefore, selecting the most appropriate EE measures to be part of a plan must not be seen as a single objective decision making problem, which aims to reach a quantitative level of energy savings. Instead, it must be seen as a process of making decisions in the presence of multiple and sometimes conflicting objectives.

Consequently, this work intends to model and provide insights for the problem of building EE plans in a multi-objective (MO) decision context considering the preferences from the decision makers (DMs) involved to identify the most appropriate plans. It is organized in sections defining the relevant objectives, defining a method to search the multi-objective space of solutions considering the preferences of the DMs, and applying the method to Portugal as a case study to illustrate the application process and gain insights on the problem. 


\section{Defining objectives}

The most obvious way to identify objectives is to engage in a discussion with the DMs about the decision situation (Keeney, 1996). The process requires creativity and hard thinking, and it can begin by asking the DM "what would you like to achieve in this situation?" The answers provided can be seen as a potential list of objectives to be analyzed more in depth.

In order to identify the ends objectives to evaluate/design EE plans and direct the possible choice of the most adequate EE measures, three key DMs were interviewed representing local and national energy agencies (Porto Energy Agency AdePorto, Portuguese Energy Agency ADENE and Brazilian Energy Research Office EPE) (Haydt et al., 2013). The interviewees were selected according to their position as DMs responsible for the promotion of EE, at local and national levels. Aiming to assess if the objectives that emerged directly from the DMs reflect all of the important consequences from the EE plans in a decision process, the list of objectives that resulted from the interviews was compared with the objectives interpreted from the ESD (European Parliament, 2006), and those found in the works from Neves (Neves et al., 2009) and Brown (Brown and Mosey, 2008). This process is described in detail in a separate work (Haydt et al., 2013). Six ends objectives were thus identified, formalizing the problem as a multi-objective one. The objectives identified are: i) to minimize the influence of energy use on climate change; ii) to minimize the financial risk from the investment; iii) to maximize the security of energy supply; iv) to minimize investment costs; v) to minimize the impacts of building new power plants and transmission infrastructures; and vi) to maximize the local air quality.

In order to make the objectives operational (possible to be evaluated), attributes associated with each objective were also identified and validated by the same DMs. The attributes identified to translate the objectives are: i) $\mathrm{CO}_{2}$ emissions savings; ii) payback period; iii) imported energy savings; iv) investment cost; v) electricity savings; and vi) total suspended particles (TSP) emissions savings (Haydt et al., 2013).

\section{Finding a method to perform oriented search}

The problem of building and evaluating EE plans was defined in the previous section as a multi-objective problem. The alternatives to choose from in this problem comprehend all the possible solutions (plans). Since there are multiple decision variables and usually there is a minimum energy savings target, the search space is considered a constrained multi-dimensional one. Such decision space is obtained by considering all the possible combinations of the available EE measures (M), and their respective degree of implementation (DI), totalizing $\mathrm{DI}^{\mathrm{M}}$ possible plans, which is usually a very high number. In order to ease the process of finding the optimal set of solutions, and also to facilitate the process of communicating the results to the DMs, it was decided to consider the adoption of the EE measures in a discrete manner, varying the application of each measure in steps of $10 \%$, regarding their maximum applicability, ranging from $0 \%$ to $100 \%$. For instance, the replacement of $0 \%, 10 \%, 20 \% \ldots$ or $100 \%$ of the stock of existing fridges may be considered.

Using the $678 \mathrm{EE}$ measures identified in (Haydt, 2011) as the available measures to be applied in a country, the size of the problem would be in the order of $11^{678}$ (considering 11 steps between $0 \%$ and $100 \%$ for the implementation degree of each measure). To tackle such a combinatorial problem, a multi-objective optimization algorithm was used, aiming at finding a varied set of non-dominated (Pareto-optimal) solutions (EE plans) such that there is no other plan that is better according to one objective without being worse according to another objective. The well-known NSGA-II algorithm was chosen to be used in this research due to the diversity encountered among non-dominated solutions (due to crowding comparison procedure), the possibility of applying constraints, the use of tournament selection to apply elitism, the possibility to work with real parameters values instead of converting to a binary genetic code, and the ability to find spread solutions and good convergence near the true Pareto-optimal front (Beyer and Deb, 2001; Deb, 2001; Deb et al., 2002). 
NSGA-II, originally conceived to find the Pareto-optimal frontier in a multi-objective problem, is able to cope with constrained multi-objective problems with the inclusion of the algorithm called "Fast Constrained-Non-Dominated Sort" (Deb et al., 2002). This algorithm does not take into account preferences among objectives, but in many real-world problems DMs may have reasons to give more importance to some objectives than to others. Since the influence of the DM preferences is part of the problem of building and selecting EE plans, it was decided to alter the NSGA-II algorithm to include this functionality. For this purpose, the outranking relations from the ELECTRE III method (Roy, 1991) were included inside the "Fast Constrained-Non-Dominated Sort" substituting the original dominance: a solution $s_{1}$ is deemed to be "dominated" if it is outranked by some other solution $s_{2}$ and $s_{1}$ does not outrank $s_{2}$ at the same time. Building a valued outranking relation constitutes the first stage of ELECTRE III; the second stage, aiming at deriving a partial ranking was not used. The outranking relation of ELECTRE III (henceforth referred to simply as ELECTRE) was considered to be suitable for aiding the decision process of building and selecting EE plans because it uses non-compensatory aggregation procedures (a very poor performance in one objective may not be compensated by a very good performance in another objective), and because it uses discrimination thresholds (indifference and preference), which lead to a preference structure where small differences of evaluations are not significant in terms of preferences, while the accumulation of several small differences may become significant, and large differences can be used to define preference. This combination of NSGA-II with the outranking relation from ELECTRE is a methodological novelty as far as the authors could assert. The detailed algorithm is explained in (Haydt, 2011).

The inclusion of the outranking relation from ELECTRE allowed the NSGA-II to cope with possible preference, indifference, and veto thresholds, and the use of weights and a cut threshold to better define the DM's preference. This NSGA-II variant has two important advantages in the context of this problem: i) it tends to remove from the population of solutions retained by NSGA-II many EE plans that, albeit possibly non-dominated, are not deemed interesting by the DMs, according to their model of preferences; and ii) it tends to forgive small differences in performance, which is useful when performance data is imprecise, preventing a plan from being eliminated if it is dominated by very small margins.

The result was a hybrid multi-objective algorithm capable of finding a (nearly) "Pareto-optimal" set of EE plans and reflecting the preferences from the DMs. This type of search does not result in a single solution, but a set of solutions. It helps the DM to have a better understanding of the whole problem and focus attention on the potentially most preferred area.

\section{DMs perspectives}

In order to make comparisons between decision outlooks, five decision perspectives were considered to be used to find the corresponding preferred EE plans. They were built internally by the research group, to generate diversity and to enable assessing the impact of different DMs' preferences on the output results. Apart from the "energy agencies" perspective, which is naturally present because the interviewed DMs represent local and national energy agencies, other perspectives were built observing how the weights could be distributed among the objectives in order to reflect diverse but somewhat typical groups of DMs. The perspectives were named according to the DM groups that they intend to represent and they are, in alphabetic order:

1. Economic Balanced - A perspective based on overweighting both the "investment costs" and the "risk of the investment". All the other objectives are considered secondary benefits with equal importance among them. Such group was created to reflect DMs that worry about the budget, but are also aware of the potential returns over time.

2. Energy Agencies - This perspective was obtained counting the number of times that each objective was mentioned at the interviews with DMs from the three energy agencies (Haydt et al., 2013). Each objective mentioned by a DM received a vote. Since not all objectives considered at this research were obtained only from the DMs, each objective also received a vote for every work reviewed that mentioned it.

3. Environmentalist - This perspective is based on overweighting all possible emissions savings $\left(\mathrm{CO}_{2}\right.$ and $\left.\mathrm{TSP}\right)$. All other objectives are considered secondary benefits with the same importance among them. As the name indicates, this 
perspective intends to represent the DMs more related to environment protection. In general, costs and nonenvironmental and non-social risks are not the main concerns for such a group.

4. Equal Weights - It is a classic approach, where no preference is given for any objective. This perspective was used mainly to find the dispersion of the alternatives in the space of results.

5. First Cost - This perspective gives more weight to the investment costs, having all the other objectives as secondary benefits with the same importance among them. This perspective tries to reflect DMs that suffer from market barriers such as lack of information about the benefits of energy efficiency and high sensitivity to initial costs.

To perform the preference based comparison among alternatives, as any other multi-criteria evaluation model, ELECTRE requires a set of parameters to model the preferences corresponding to these five perspectives. The parameters are: the weight of each objective, the cut, the indifference and the preference thresholds (veto thresholds were not used in this analysis).

The first parameter that needs to be specified is the weight of each objective. Unlike other methods, in which weights are used to convert performance into a common value scale, the weights defined in ELECTRE are not influenced by the scale on which performances are measured, making its definition much simpler because they must only reflect the abstract importance of each objective to the DM. Table 1 presents the weights considered for each DM's perspective.

Table 1 - Weights according to decision makers' perspectives to evaluate plans

\begin{tabular}{|l|r|r|r|r|r|r|}
\hline \multicolumn{1}{|c|}{ Perspective } & \multicolumn{1}{c|}{$\begin{array}{c}\text { CO2 } \\
\text { Savings }\end{array}$} & \multicolumn{1}{c|}{$\begin{array}{c}\text { TSP } \\
\text { Savings }\end{array}$} & $\begin{array}{c}\text { Imported } \\
\text { Energy Savings }\end{array}$ & $\begin{array}{c}\text { Electricity } \\
\text { Savings }\end{array}$ & $\begin{array}{c}\text { Investment } \\
\text { Cost }\end{array}$ & Payback \\
\hline Economic Balanced & 0.05 & 0.05 & 0.05 & 0.05 & 0.40 & 0.40 \\
\hline Energy Agencies & 0.12 & 0.09 & 0.48 & 0.09 & 0.11 & 0.11 \\
\hline Environmentalist & 0.40 & 0.40 & 0.05 & 0.05 & 0.05 & 0.05 \\
\hline Equal Weights & 0.16 & 0.16 & 0.16 & 0.16 & 0.16 & 0.16 \\
\hline First Cost & 0.10 & 0.10 & 0.10 & 0.10 & 0.50 & 0.10 \\
\hline
\end{tabular}

The second key parameter is the cut threshold. This threshold corresponds to the value that defines when an alternative outranks another. Given two alternatives ( $a$ and $b$ ), when the sum of the weights of the objectives in which $a$ is not worse than $b$ exceeds the cut threshold, then it is considered that $a$ outranks $b$. If $b$ does not outrank $a$ at the same time, then $a$ is considered to be preferred to $b$. The cut thresholds were defined trying to reflect the outranking conditions (in terms of supporting criteria) required by each DM's perspective. The cut thresholds identified were:

- $\lambda=0.85$ for the economic balanced and for the environmentalist perspectives, thereby requiring at least the agreement of the two objectives with weight 0.40 and one of the objectives with weight 0.05 to support an outranking assertion;

- $\lambda=0.80$ for the energy agencies perspective, thereby requiring at least the agreement of four objectives, including mandatorily imported energy savings, $\mathrm{CO} 2$ savings, and one of the criteria with weight 0.11 , to support an outranking assertion;

- $\lambda=0.70$ for the first cost perspective, thereby requiring the agreement of Investment Cost plus at least two more objectives, to support an outranking assertion;

- $\lambda=1$ for the equal weights perspective; this value was attributed to have a decision perspective of unanimity.

It is also necessary to determine, for each objective considered, the degree of differences that the DMs would consider sufficiently large in order to warrant that one alternative is really superior to another in that objective. For that, ELECTRE uses the indifference threshold and the preference threshold (Roy, 1991). The indifference threshold allows modeling what the DM considers to be a situation of indifference for a given objective: if the difference between two alternatives on that objective does 
not exceed the indifference threshold, then the DM is not convinced that an alternative is really better than the other one according to that objective, since performances are not precise measurements. An indifference threshold of 5\% was used in this work to reflect the inherent uncertainty in the input data, gathered from several sources, and the simplifications in the energy modeling process. The preference threshold allows modeling what the DM considers to be a situation of strict preference: if the difference between two alternatives on some objective attains or surpasses the preference threshold, then the DM asserts that an alternative is better than the other one according to that objective. A preference threshold of $10 \%$ was considered to be adequate in this work. If a difference of performance is in between the indifference and preference thresholds, this corresponds to a situation of "weak preference" (Roy, 1991).

\section{Using the hybrid NSGA-II to perform oriented search for national energy efficiency plans}

The hybrid NSGA-II algorithm was adapted to find solutions for the problem of searching for the feasible EE plans. An outline of the mathematical formulation of the problem, including its constraints, is described by equations 1 to 9 .

$$
\begin{aligned}
& \operatorname{Min} \sum_{m=1}^{n} \operatorname{InvestmentCost}(m) \times \text { measureSize }(m) \\
& \operatorname{Max} \sum_{m=1}^{n} \mathrm{CO}_{2} \text { EmissionsSavings }(m) \times \text { measureSize }(m) \\
& \operatorname{Max} \sum_{m=1}^{n} \text { ImportedEnergySavings }(m) \times \text { measureSize }(m) \\
& \operatorname{Max} \sum_{m=1}^{n} \text { TSPEmissionsSavings }(m) \times \text { measureSize }(m) \\
& \operatorname{Max} \sum_{m=1}^{n} \text { ElectricitySavings }(m) \times \text { measureSize }(m) \\
& \operatorname{Min} \frac{\sum_{m=1}^{n} \text { InvestmentCost }(m) \times \text { measureSize }(m)}{\sum_{m=1}^{n} \text { MonetaryBenefits }(m) \times \text { measureSize }(m)}
\end{aligned}
$$

equation 1

equation 2

equation 3

equation 4

equation 5

equation 6

The constraints are translated by equations 7 to 9 :

$$
\begin{aligned}
& g 1(\text { plan })=\frac{\sum_{m=1}^{n} F E S(m, y) \times \text { measureSize }(m)}{T F E(y)} \times 100 \geq 9 \% \quad \text { equation } 7
\end{aligned}
$$

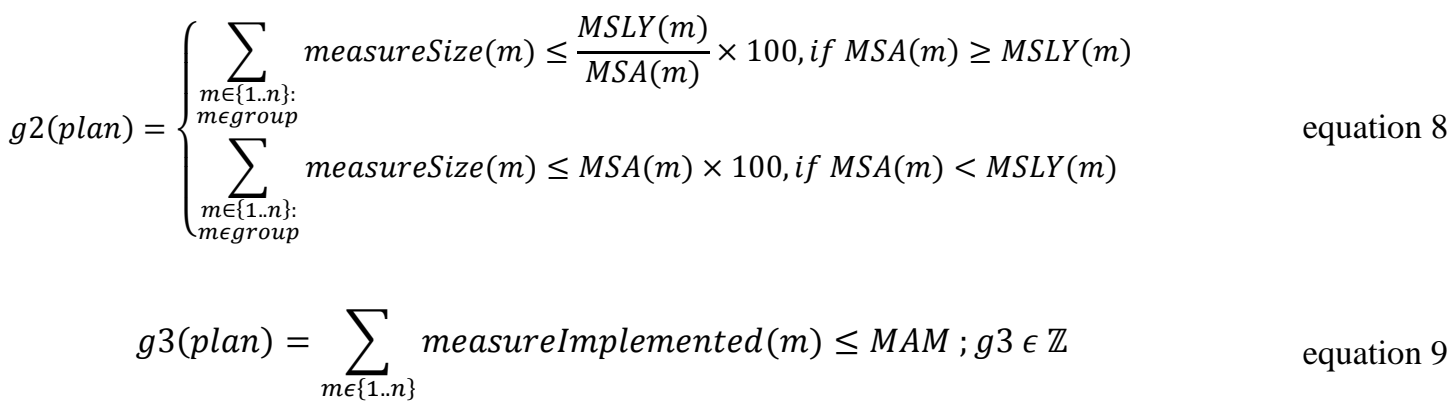


with measureImplemented $(m)=\left\{\begin{array}{l}1, \text { if measureSize }(m)>0 \\ 0, \text { if measureSize }(m)=0\end{array}\right.$

Where:

n: Total number of measures

group: Group of measures that affects the same end - use and energy carrier

measureSize $(m) \in[0,100 \%]$

InvestmentCost $(m)$ : The cost of investing in measure $m$

$\mathrm{CO}_{2}$ EmissionsSavings $(\mathrm{m})$ : The savings of $\mathrm{CO}_{2}$ Emissions from measure $m$

ImportedEnergySavings $(m)$ : The reduction in imported energy due to measure $m$

TSPEmissionsSavings $(m):$ The reductions in TSP emissions due to measure $m$

ElectricitySavings(m): The reductions in electricity due to measure $m$

MonetaryBenefits $(m)$ : The monetary benefits from measure $m$

FES $(m, y)$ : Final energy savings for measure $m$ at the result year $y$ (last year from the plan)

TFE(y): Total final energy use at year $y$

MSA(m): Maximum size that measure $m$ can be physically applied

$\operatorname{MSLY}(m):$ Maximum size that measure $m$ can have at the last year of the plan

MAM: Maximum number of measures allowed to be in one plan $(M A M \in \mathbb{Z})$

In this simplified outline of the mathematical formulation, the decision variables are the sizes of the measures potentially included (measureSize(1), ..., measureSize(n)). The minimizations and maximizations above represent the intended objectives. The first constraint (equation 7) represents the minimum 9\% final energy savings target in relation to the last year of the application of the plan (for the case study presented in the next section, the last year is 2016, assuming the starting year was 2008). Both the 9\% savings and the definition of the last year of the application of the plan, as the ninth year after the start of the plan, are based on the ESD (European Parliament, 2006). The second constraint (equation 8) limits the size of the measures affecting each end-use and energy carrier, which shall not be higher than the projected size of the respective usage indicator (e.g. ownership). In other words, the formulation does not allow the size of any measure to exceed what is physically implementable in the country.

It is important to remind that the problem is of non-linear nature, since there can be interactions between some measures that result in fewer benefits than the sum of the individual benefits if the measures were applied separately to the same beneficiary. However, for the application of most of the measures, the observed behavior is linear. The non-linear case is observed, for example, if insulation measures and better heating systems are applied simultaneously to the same house. Those non-linear behaviors are taken into account by the non-linear energy model developed in (Haydt, 2011). However, due to unpractical high computational time when applied together with the hybrid optimization algorithm, it was decided to use a linear simplification (described above). To guarantee the linear behavior, and therefore no overestimation or underestimation of the results, no beneficiary (e.g. individual, house, industry) can have more than one EE measure affecting the same end-use. For instance, in the 
model one house can benefit from changing the fridge and improving its insulation, but cannot have the heating system changed and the thermal insulation improved, or can have the heating system changed twice (from whatever to something using biomass and later to heating pumps). This is made possible by the second constraint (equation 8), which places limits to the total size of the measures targeting the same end-use and energy carrier. This imposition does not seem to have the potential to introduce significant effects in the results, as it is true that in practice an overall higher effect is obtained if measures on the thermal performance are applied to different buildings than if they are applied to the same ones.

The third constraint (equation 9) was introduced because the plans need to have a concise number of measures to be manageable, as well as to reduce the search space to try to ease the converging process of the algorithm. For this, a tentative maximum of 100 measures was adopted.

After formulating the problem, it was necessary to verify the search consistency in the path for the Pareto-optimal frontier. For that, the algorithm was applied to the Portuguese energy system, modeled for 2006. The energy agency perspective was chosen as a reference perspective to all consistency tests because it was the only perspective that came from real DMs. There were 678 available EE measures with 11 implementation steps (between 0\% and 100\% in a 10\% step; e.g. replacing 0\%,10\%, 20\% ...100\% of the fridges stock for more efficient ones), in line with Brown (Brown and Mosey, 2008; Haydt, 2011).

To perform this test, 10 runs were made, using 1000 generations, bringing in each run around 100 preferred solutions (solutions such that no other solutions in the population are preferred to them, i.e., all other solutions either do not outrank them or the outranking is reciprocal). Each run differs from the other only in terms of the initial populations, which are randomly created at the beginning of the run. Figure 1 shows the range of the values of the objectives from the preferred solutions that resulted from the algorithm in each run.

Since the problem is of enormous size $\left(11^{678}\right.$ possible alternatives, considering $678 \mathrm{EE}$ measures and varying their implementation from $0 \%$ to $100 \%$ in a $10 \%$ step), it was not expected that the algorithm would converge to the "Pareto-optimal" frontier, but it was fairly acceptable to yield a near Pareto-optimal frontier. Therefore, assuming such behavior, it was determined to perform a consistency check on the results of different runs in order to guarantee at least the robustness of the search, by comparing the range of the values found for each objective in each different run, and by observing how similar are the solutions obtained across the different runs. If the range and the solutions were similar in all runs, consistency was deemed good and any result from any future run would be accepted for assessment. The consistency check is shown in Figure 1, which also presents a comparison between all solutions in all runs in order to find where the preferred solutions would lay if all results came from the same run. It shows that the best set of preferred solutions would be found in run 6 (marked). 

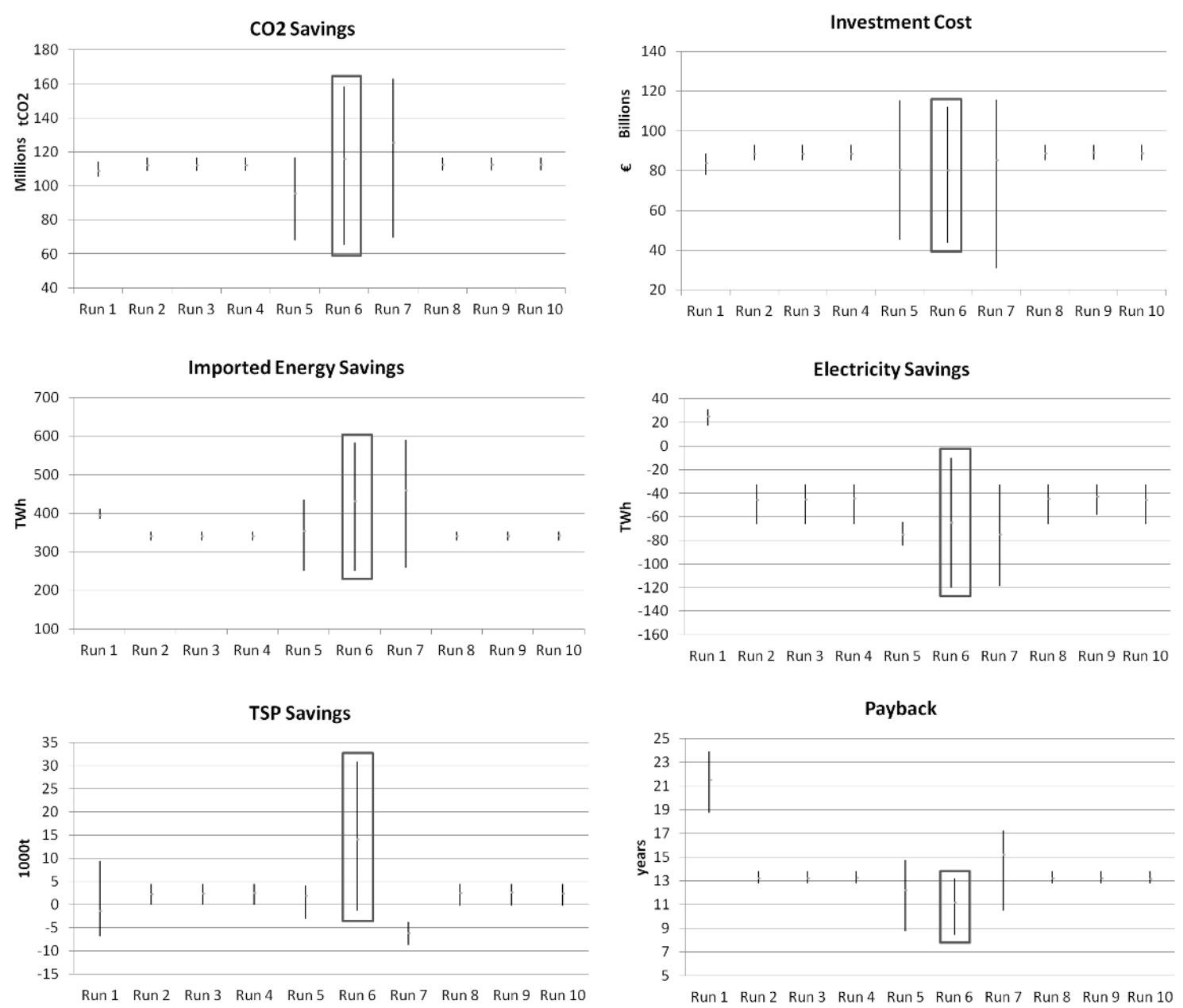

Figure 1 - Range of objectives by run, energy agencies perspective using $678 \mathrm{EE}$ measures

The lack of consistency in the results among runs would compromise the confidence in any conclusion. Therefore, to overcome this problem, it was decided to test the possibility of introducing at an early stage a screening of the measures according to the DMs' perspectives, and to bring to the hybrid-NSGA-II only the most adequate measures. These were identified according to each decision perspective in a comparison of individual measures belonging to same end-use and sector. The model was forced to include the best measures from each sector, in order to foster diversity for the plans in the following stage.

\section{Screening of measures and initial results for Portugal}

The problem of lack of consistency in the results from different runs was perceived to be strongly influenced by the size of the problem (search space). Consequently, the search space was reduced by decreasing the number of available EE measures that are allowed to enter the combinatorial framework of constructing plans. As described in the final paragraph of the previous section, this reduction was not done by arbitrarily removing measures. Instead, an early screening process of the measures, performed using the outranking relation of ELECTRE, was introduced to select the most fitted measures for each sector according to each DM's perspective. Therefore, the same five decision perspectives (economic balanced, energy agencies, environmentalist, equal weights and first cost) were also considered to evaluate the measures individually, i.e. before evaluating them as groups of measures.

Since in this new stage it is the individual measures that are evaluated (and not entire plans), two additional criteria were also considered. The first criterion was the lifetime, which was added because it was mentioned by the interviewed DMs as a representation of the benefits from the measures throughout time. The second criterion was the potential final energy savings in the last application year of the measure. This was added to somehow transpose the restriction of reaching final energy savings to 
the evaluation of measures. Some measures have high individual final energy savings, but may also have low total energy savings potential due to a restricted scale of application (e.g. low penetration of the technology that will be replaced). Therefore, to avoid that such measures would be preferred and consequently lead to not being possible to reach the energy saving targets, the potential final energy savings criterion was introduced. Due to the importance of satisfying the constraints of the problem (overall savings target), it was decided to give high weight to the potential final energy savings in all the DM's perspectives.

Table 2 presents the weights according to the DMs' perspectives. The indifference and the preference thresholds were set as described in Section 4 (5\% and 10\%, respectively). The cut thresholds were set to 0.8 for all perspectives except the equal weights, which used a value of 1 (unanimity requirement).

Table 2 - Weights according to decision makers' perspectives to evaluate measures

\begin{tabular}{|l|r|r|r|r|r|r|r|r|}
\hline \multicolumn{1}{|c|}{ Perspective } & $\begin{array}{c}\text { Potential } \\
\text { Final } \\
\text { Energy } \\
\text { Savings }\end{array}$ & \multicolumn{1}{c|}{$\begin{array}{c}\text { CO2 } \\
\text { Savings }\end{array}$} & $\begin{array}{c}\text { TSP } \\
\text { Savings }\end{array}$ & $\begin{array}{c}\text { Imported } \\
\text { Energy } \\
\text { Savings }\end{array}$ & $\begin{array}{c}\text { Electricity } \\
\text { Savings }\end{array}$ & $\begin{array}{c}\text { Investment } \\
\text { Cost }\end{array}$ & Payback & Lifetime \\
\hline $\begin{array}{l}\text { Economic } \\
\text { Balanced }\end{array}$ & 0.25 & 0.05 & 0.05 & 0.05 & 0.05 & 0.25 & 0.25 & 0.05 \\
\hline Energy Agencies & 0.24 & 0.20 & 0.03 & 0.23 & 0.03 & 0.12 & 0.12 & 0.03 \\
\hline Environmentalist & 0.25 & 0.25 & 0.25 & 0.05 & 0.05 & 0.05 & 0.05 & 0.05 \\
\hline Equal Weights & 0.125 & 0.125 & 0.125 & 0.125 & 0.125 & 0.125 & 0.125 & 0.125 \\
\hline First Cost & 0.46 & 0.05 & 0.05 & 0.05 & 0.05 & 0.24 & 0.05 & 0.05 \\
\hline
\end{tabular}

The outranking relation of ELECTRE was used for screening the preferred EE measures in groups defined by the sector, subsector and end-use. This approach was chosen to guarantee that there would be measures available from all sectors (diversity). By following this approach, excluding a measure is justified by the existence of a superior measure that is comparable to it in terms of purpose and scope.

The screening process allowed to find the most fitted measures for each DM perspective and to reduce the available measures, and consequently, the search space when combining the measures to build plans. It resulted in sets of $80,85,92,98$ or 244 EE measures selected for the next stage, respectively for the cases of the first cost, energy agencies, environmentalist, economic balanced and equal weights perspectives. Each set of measures is presented at annex I (supplementary material).

After screening the measures, the search for the feasible alternatives (EE plans as combinations of measures) was performed, starting by the energy agencies perspective, considering only the 85 selected measures and using 1000 generations in a total of 10 runs starting from randomly created populations. Figure 2 presents the results. The results now show good consistency on the range of the performances for almost all runs, excluding run 2 which had very particular results. Figure 2 also presents a comparison between all solutions in all runs in order to find where the preferred solutions are. The best sets of preferred solutions can be found in runs 5, 7 and 9 (marked), totaling 88 solutions from almost 1000 solutions in all 10 runs. The fact that preferred solutions' ranges were similar across different runs also shows a good consistency in the results. 

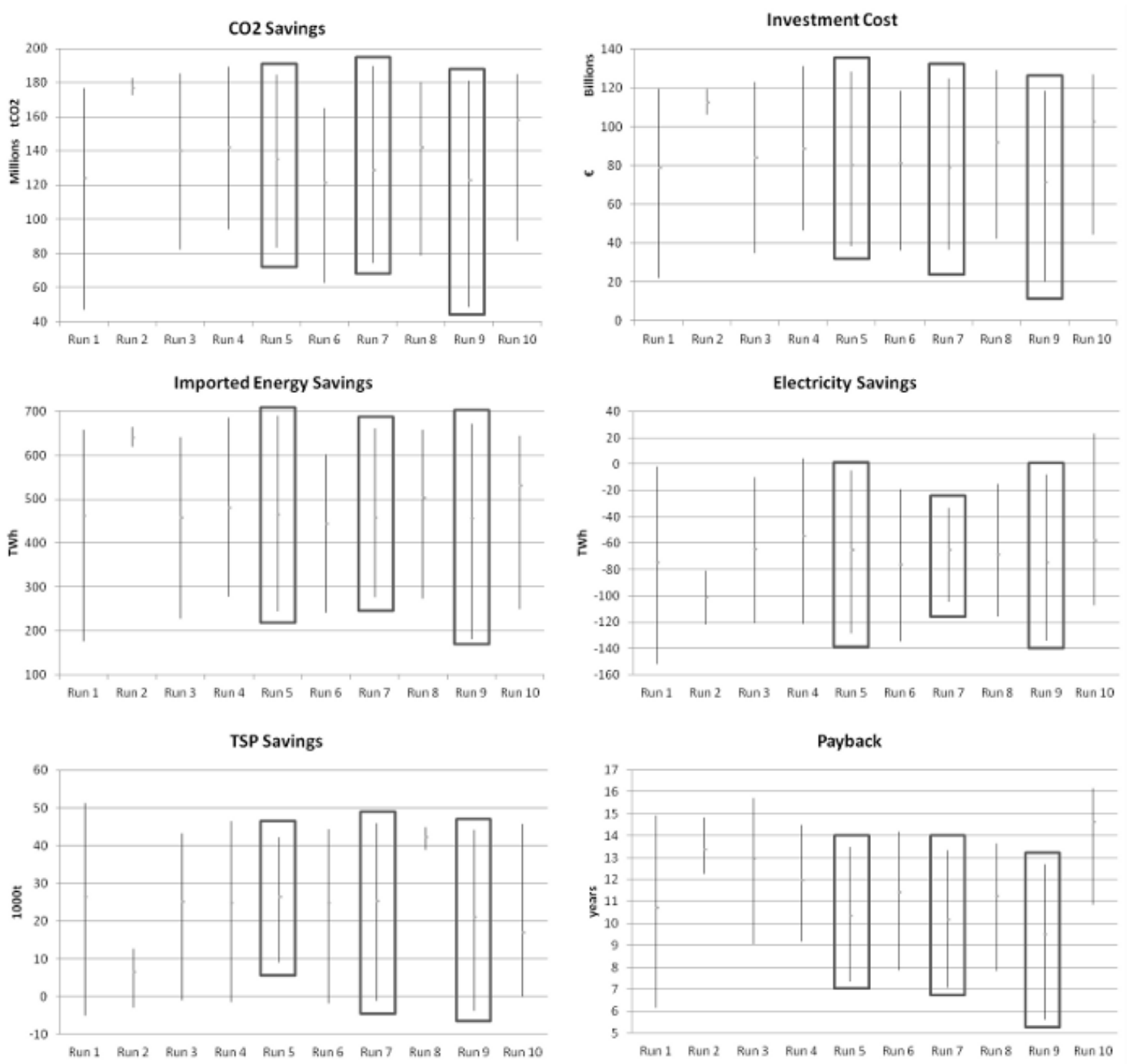

Figure 2 - Range of objectives by run, energy agencies perspective using 85 EE measures

To assess whether the screening process was excluding interesting solutions, the preferred alternatives from the search using the screening process were compared with the preferred alternatives from the search using the $678 \mathrm{EE}$ measures previously presented in section 5. The main finding from this comparison was that all alternatives found using the screening process were preferred to the alternatives found without using it. The better and more dispersed values of the objectives (Figure 3) are also associated with higher and more dispersed final energy savings, presented in Figure 4. This shows that the process with the initial screening of measures actually results in identifying globally better solutions than without it. 
CO2 Savings

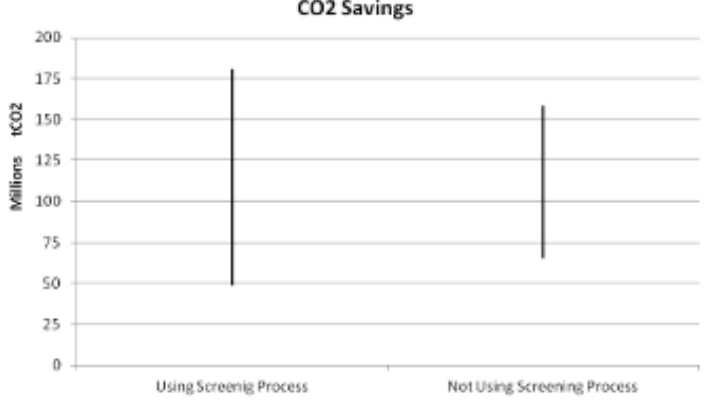

Imported Energy Savings
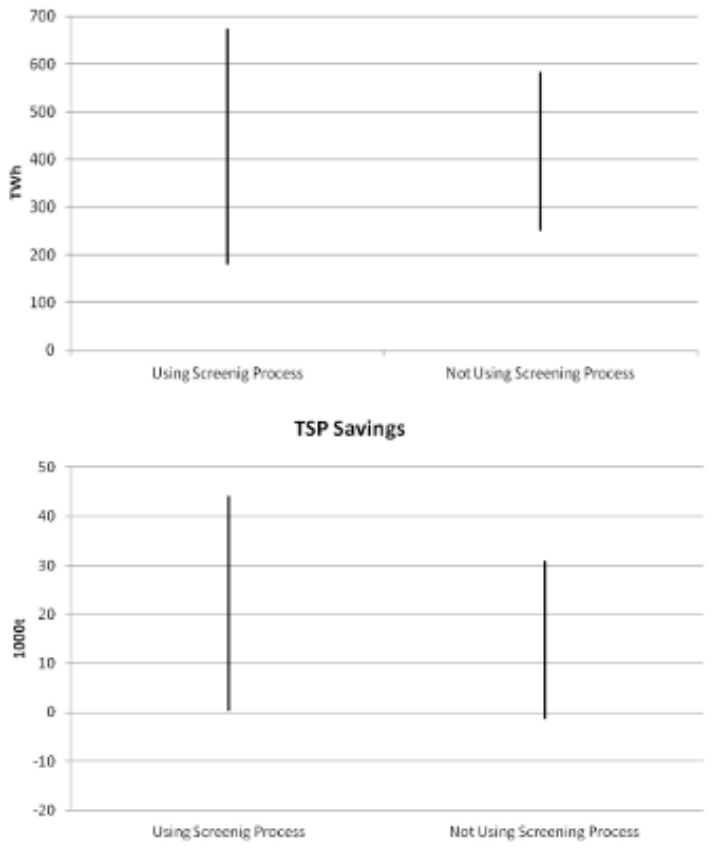

Investment Cost

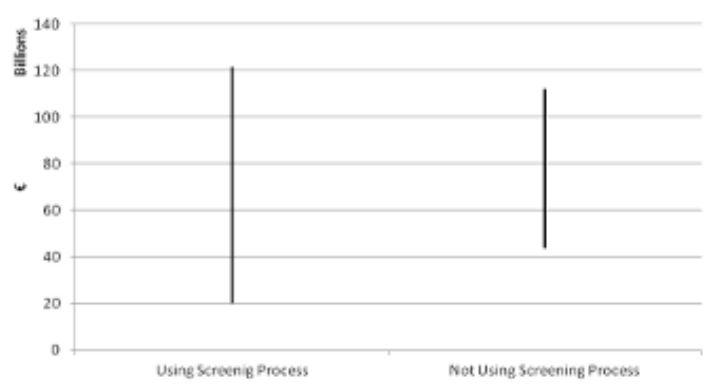

Electricity Savings

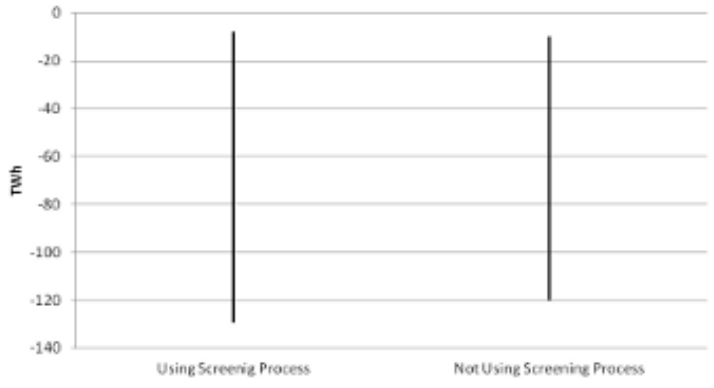

Payback

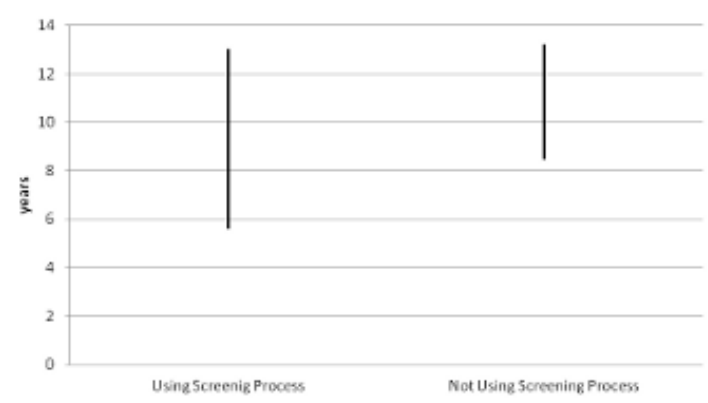

Figure 3 - Results for the energy agencies perspective using and not using the screening process

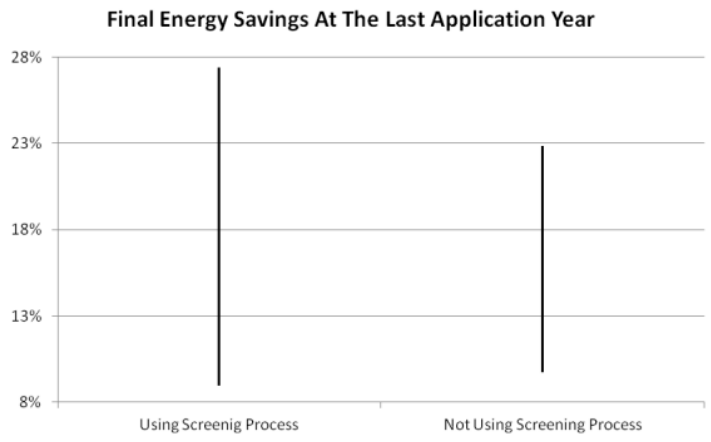

Figure 4 - Range of plans at the last application year, in percent of final energy savings

Observing Figure 3 and Figure 4, it is possible to establish a first assessment about the range of values that can be achieved in each objective and the possible savings in relation to the last application year. Such values are probably unknown to policy and DMs when establishing initial targets; therefore, those results by themselves are already useful to the decision making process.

\section{Portugal as a case-study: results across the decision maker's perspectives}

Five DMs' perspectives were considered (as defined in section 4), in order to get more insights on to which extent may the preferences of the DMs influence the final sets of measures in plans, and also to which extent is it possible to achieve the 
fundamental objectives. Following the same process used in section 6 , but now for all the decision perspectives, 10 runs were executed using randomly created populations based on the respective pre-selected group of measures.

The first analysis made on the results from all searches was to quantify how many EE measures were picked from the available measures to form plans according to each DM perspective, as shown in Figure 5. Independently of the perspective, there was no plan that used all the measures available. Furthermore, there were always a few measures that were never selected to be in any plan.

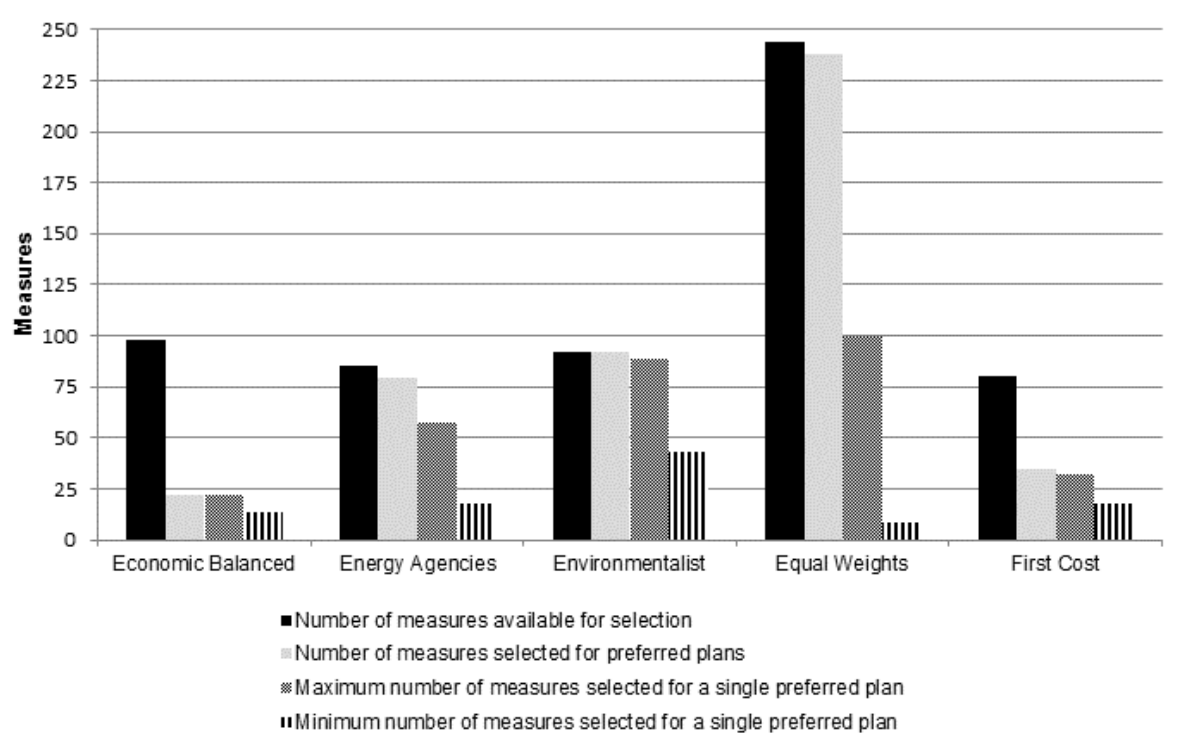

Figure 5 - Assessment of the available (after screening) and the picked EE measures to compose EE plans according to the decision makers' perspective

Assessing the plans in all perspectives makes it possible to find how frequently EE measures were selected to be in plans. Table 3 lists the main EE measures sorted by the frequency of appearance in all preferred plans considering all DMs' perspectives except Equal Weights. The Equal Weights perspective was not included in this comparison because it does not really reflect a decision preference and the appearance of measures in plans under this perspective was much dispersed. The top 20 measures vary their presence in plans from nearly all plans (substitution of lamps for more efficient high intensity discharge lamps in the services sector) to $48 \%$ of the plans (replacement of motors with output range higher than $500 \mathrm{~kW}$ for most efficient ones in the industry sector), and include measures from the four sectors (domestic, industry, services and transports).

The top measures by frequency of appearance in plans are very reassuring in what concerns the current policies in Portugal, and somehow around the globe. Indeed, besides the measures to promote the use of electric trucks, which are a very recent technology and may cause concerns about its implementation, all the other measures are mature and represent the most recent EE policies in use. The high use of technologies based on electricity, as listed in Table 3, confirms the benefits of the trend for more endogenous and less carbon intensive power generation mix observed in Portugal in recent years.

Examining the range of values reached for each objective and for each DM's perspective, presented in Figure 6 and Figure 7, it is possible to observe the relation between the decision perspective and the objectives achieved. The results in Figure 6 are reassuring about the preferences of the DMs, since higher $\mathrm{CO}_{2}$ and TSP emissions savings are encountered for the perspective which values most these objectives (environmentalist), lower costs were found for the First Cost perspective and higher imported energy savings were found for the Energy Agencies perspective. As expected, the Equal Weights perspective led to values for the objectives very dispersed in all objectives. The First Cost and the Economic Balanced perspectives presented, in general, the lowest values for those objectives and stayed close to the restriction of a minimum of $9 \%$ savings. However, the lowest payback found for a plan was encountered in a search guided by the preferences from the Energy Agencies perspective. 
Comparing the measures of Table 3 (top 20 measures for all perspectives) with the current EE plan for Portugal (Resolução do Conselho de Ministros $n^{\circ}$ 80/2008. DR 97 SÉRIE I, 2008), it is possible to find that most of the technological based measures in the current plan somehow match the measures in the table. The word "somehow" is used due to the lack of description of the measures from the current EE plan for Portugal, therefore, demanding some interpretation. It is possible to match measures such as:

- Improvements in the bus fleet to low emission buses (any type).

- Incentives to replace refrigerators, freezers, washing machines and lamps for more efficient ones (fitting in class A or $\mathrm{A}+)$.

- Incentives to use heat pumps with high efficiency.

- Substitution of office equipments for more efficient ones, such as laptops.

- Measures related to more efficient electric motors and lighting in the industry sector.

- Incentives to more efficient heat production in the industry sector.

- Improvements in public lighting.

In a global analysis, the current EE plan for Portugal seems to have its core measures belonging to the set of the most relevant ones encountered in this research. Despite the need for better and clearer specifications on the details and the calculations behind the savings, the national Portuguese plan appears to be a plan technically fitted to Portugal. 
Table 3 - Degree of adoption of the main EE measures by the preferred plans of all decision makers' perspectives (except equal weights)

\begin{tabular}{|c|c|c|c|c|c|c|}
\hline sector & sub-sector & target end-use & $\begin{array}{l}\text { target energy } \\
\text { carrier }\end{array}$ & $\begin{array}{l}\text { energy } \\
\text { carrier }\end{array}$ & measure & $\begin{array}{l}\text { Adopted in } \\
\% \text { of plans }\end{array}$ \\
\hline Services & All Services & Lighting & Electricity & Electricity & Substitution of lamps for more efficient high intensity discharge lamps & 99 \\
\hline Domestic & All Households & Freezing & Electricity & Electricity & Substitution of freezers for more efficient freezers in market $(\mathrm{A}++)$ & 96 \\
\hline Transports & Freight & Truck & Diesel & Electricity & Substitution of trucks for more efficient electric trucks & 73 \\
\hline Domestic & All Households & Lighting & Electricity & Electricity & Substitution of lamps for more efficient compact fluorescent lamps & 71 \\
\hline Services & All Services & Ambient Heating & $\begin{array}{l}\text { Diesel for } \\
\text { Heating }\end{array}$ & Electricity & $\begin{array}{l}\text { Replacement of ambient heating systems for more efficient centralized electric heat pump } \\
\text { systems }\end{array}$ & 71 \\
\hline Domestic & All Households & Ambient Cooling & Electricity & Electricity & Replacement of ambient cooling systems for more efficient air conditioning & 69 \\
\hline Industry & Paper & Motors & Electricity & Electricity & Replacement of motors with output range between 130 and $500 \mathrm{~kW}$ for more efficient ones & 68 \\
\hline Services & All Services & Motors & Electricity & Electricity & Replacement of motors with output range between 4 and $10 \mathrm{~kW}$ for more efficient ones & 66 \\
\hline Industry & $\begin{array}{l}\text { Metal Machinery } \\
\text { and Electro }\end{array}$ & Lighting & Electricity & Electricity & Substitution of lamps for more efficient high intensity discharge lamps & 62 \\
\hline Industry & Paper & Motors & Electricity & Electricity & Replacement of motors with output range between 4 and $10 \mathrm{~kW}$ for more efficient ones & 61 \\
\hline Domestic & All Households & Clothes Washing & Electricity & Electricity & Replacement of washing machines for more efficient ones (label A, A+) & 59 \\
\hline Domestic & All Households & Computers & Electricity & Electricity & Replacement of computers for more efficient laptops & 57 \\
\hline Transports & Freight & Truck & Gasoline & Ethanol & Substitution of trucks for more efficient ethanol (E85) trucks & 57 \\
\hline Domestic & All Households & Clothes Drying & Electricity & Electricity & Replacement of tumble dryers for more efficient electric ones (label A, A+) & 56 \\
\hline Services & All Services & Public Lighting & Electricity & Electricity & Substitution of lamps for more efficient LEDs & 56 \\
\hline Services & All Services & Motors & Electricity & Electricity & Replacement of motors with output range between 70 and $130 \mathrm{~kW}$ for more efficient ones & 54 \\
\hline Domestic & All Households & Ambient Heating & Biomass & Electricity & $\begin{array}{l}\text { Replacement of ambient heating systems for more efficient centralized electric heat pump } \\
\text { systems }\end{array}$ & 53 \\
\hline Domestic & All Households & Cooking & Biomass & Natural Gas & Replacement of hobs for more efficient natural gas hobs & 50 \\
\hline Industry & Cement & Boiler Use & Other & Natural Gas & Substitution of boilers for more efficient natural gas CHP & 49 \\
\hline Industry & Cement & Motors & Electricity & Electricity & Replacement of motors with output range higher than $500 \mathrm{~kW}$ for more efficient ones & 48 \\
\hline
\end{tabular}



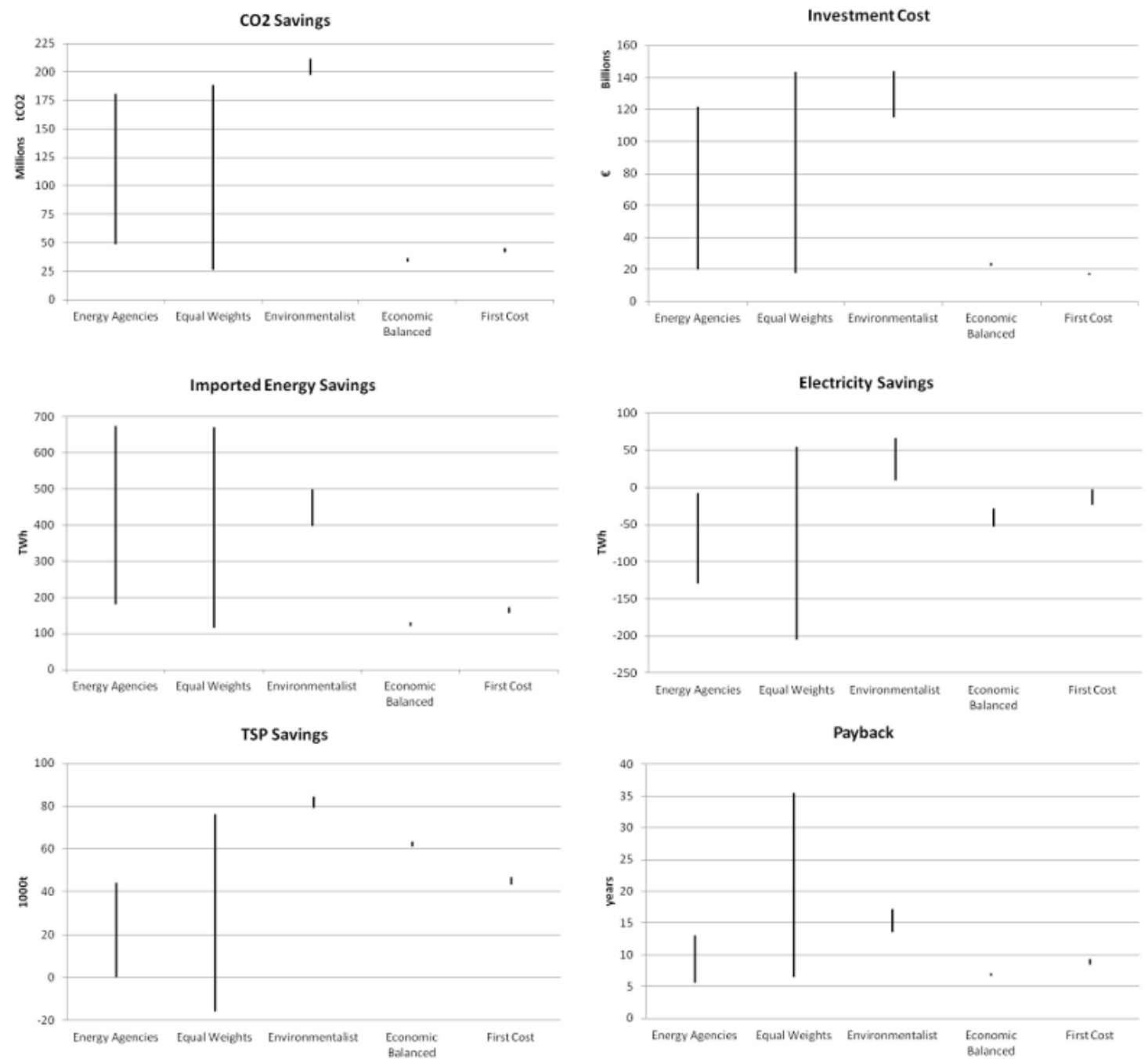

Figure 6 - Range of objectives of the preferred plans by decision makers' perspective

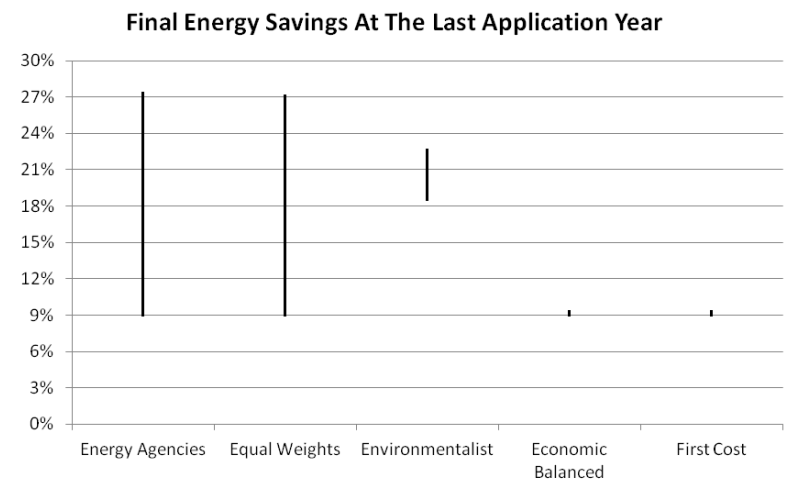

Figure 7 - Range of percentage final energy savings at the last application year, in the preferred plans of each decision maker perspective 
In order to assess how the results from the plans behave in the six dimensions of the problem, the "best" limit values for each objective (among all the plans found) are listed in Table 4. The results are not directly comparable because each perspective reflects the preferences of the respective DM. However, the limit solutions can be compared to observe the "trade-offs" between their objectives to achieve the "best" value in one. In addition, this table brings a numerical confirmation of the expected results from each DM's perspective. An interesting analysis regarding Table 4 is to compare the two plans that achieved exactly the minimum proportional final energy savings, 9\%. Both plans are derived from different decision preferences. They illustrate the fact that there exists more than one plan capable of reaching the targets and showing different benefits for the objectives. Table 4 also shows that the payback is not directly related to the investment cost, and, despite the investment cost and the TSP savings, the plan presented by the First Cost has no better objectives' results than the one presented by the energy agencies' perspective. Actually, if both plans were compared by the energy agencies' perspective, the second solution (from the Energy Agencies) would be preferred.

Table 4 - Achievement of Objectives and final energy savings for plans with limit (best possible) values of attributes

\begin{tabular}{|c|c|c|c|c|c|c|c|c|}
\hline Limit & Perspective & $\begin{array}{l}\text { Final } \\
\text { energy } \\
\text { savings }\end{array}$ & $\begin{array}{l}\text { CO2 emissions } \\
\text { savings } \\
\text { (MtCO2) }\end{array}$ & $\begin{array}{l}\text { Investment } \\
\text { cost (M€) }\end{array}$ & $\begin{array}{l}\text { Imported } \\
\text { energy } \\
\text { savings } \\
\text { (TWh) }\end{array}$ & $\begin{array}{l}\text { Electricity } \\
\text { savings } \\
\text { (TWh) }\end{array}$ & $\begin{array}{c}\text { TSP } \\
\text { emissions } \\
\text { savings (kt) }\end{array}$ & $\begin{array}{c}\text { Payback } \\
\text { (years) }\end{array}$ \\
\hline $\begin{array}{l}\max . \mathrm{CO} 2 \\
\text { savings }\end{array}$ & Environmentalist & $20.6 \%$ & 212 & 135,021 & 449 & 27 & 81 & 16.7 \\
\hline $\begin{array}{l}\text { min. } \\
\text { Investment } \\
\text { cost }\end{array}$ & First Cost & $9.0 \%$ & 43 & 16,673 & 159 & (14) & 46 & 8.5 \\
\hline $\begin{array}{l}\text { max. } \\
\text { Imported } \\
\text { energy } \\
\text { savings }\end{array}$ & Energy Agencies & $27.2 \%$ & 181 & 121,811 & 673 & $(108)$ & 38 & 13.0 \\
\hline $\begin{array}{l}\max . \\
\text { Electricity } \\
\text { savings }\end{array}$ & Environmentalist & $19.2 \%$ & 198 & 134,033 & 409 & 66 & 84 & 14.1 \\
\hline $\begin{array}{l}\text { max. TSP } \\
\text { savings }\end{array}$ & Environmentalist & $19.2 \%$ & 198 & 134,033 & 409 & 66 & 84 & 14.1 \\
\hline $\begin{array}{l}\text { min. } \\
\text { Payback }\end{array}$ & Energy Agencies & $9.0 \%$ & 49 & 20,184 & 181 & (11) & 37 & 5.6 \\
\hline
\end{tabular}

The analysis performed in this section, using multiple DMs' perspectives, allowed the confirmation that the proposed approach to the problem of finding EE plans is respecting the DMs' preferences. It also enables the identification of the more consistent measures independently of the used preferences, and it gives insights about how much can be achieved in each objective and the possible "trade-off" in the other objectives. A DM could, at this stage, also request some further constraints to be respected (e.g., an upper bound on investment costs) and repeat the analysis to obtain a more refined set of solutions.

\section{Conclusions}

This work aimed at providing the use of a multi-objective optimization algorithm to search for the EE plans most fitted to the DMs' preferences. The DMs' objectives, obtained through a value-focused thinking process, were i) to minimize the influence of energy use on climate change; ii) to minimize the financial risk from the investment; iii) to maximize the security of energy supply; iv) to minimize investment costs; v) to minimize the impacts of building new power plants and transmission infrastructures; and vi) to maximize the local air quality.

In order to help DMs to have a better understanding of the whole problem, showing the limits of what can be achieved regarding each objective and giving insights to assess possible "trade-offs" when choosing a plan, a population-based multi- 
objective approach was followed. The chosen algorithm was the well-known NSGA-II, which provides a set of widely dispersed non-dominated solutions, not taking any preferences into account. This algorithm was adapted to use the outranking relations preference model of ELECTRE III. The fusion of the NSGA-II and the ELECTRE is a novel approach and a contribution to the decision making process. One important advantage of using such approach compared to the use of the conventional NSGA-II is the introduction of preference among objectives, thereby excluding regions in the objective space in which the DM would not be interested. Another advantage is the possibility to select the solutions considering inaccurate or imprecise data (by using indifference and preference thresholds).

In order to test the use of the methodology and gain some insights, Portugal was used as a case study. With the intent of getting more insights from the decision process, it was decided to build and compare five different DM's perspectives (Energy Agencies, Environmentalist, Equal Weights, First Cost and Economic Balanced). For each perspective, a preselection of the EE measures most fitted to the respective decision-maker preferences was performed. This was necessary to ensure good consistency between different runs of the algorithm, but it also contributed to improve the quality of the solutions identified. The measures available for each group were compared in order to find the top transversal measures used in all plans. Using the top measures as a base of comparison, it was found that most of the measures promoted by the existing EE plan for Portugal find a reasonable correspondence to the measures in that list.

It was observed that most of the EE measures chosen by the multi-objective algorithm to be present in plans for Portugal are focused on the use of electricity, by recommending the adoption of more efficient systems in replacement of the current ones also using electricity, or by recommending an energy shift to electricity, in this case rising the use of electricity instead of saving electricity. Since the electric generation mix and their characteristics for the period evaluated by the search algorithm (2008-2016) are considered exogenous inputs based on the current policies applied to the power system (APREN, 2010; Conselho de Ministros, 2010), such "preference" for electricity reflects the ongoing developments to reduce the environmental loads and to increase the use of endogenous renewable resources in the Portuguese power generation system. The use of endogenous resources may nevertheless impact on the results of TSP emissions, since the increased use of biomass would increase the emission of particles (considering the current use of filters in each sector).

Observing the range of values for each objective under all the DMs' perspectives used at the Portuguese case study, it was possible to confirm that the plans that achieved the "best" values on individual objectives were found in the plans reflecting the objectives that the DMs valued the most. Globally, considering all decision perspectives, several different preferred plans were identified, with ranges between $9 \%$ and $27 \%$ for the final energy savings, between $26 \mathrm{MtCO}_{2}$ and $212 \mathrm{MtCO}_{2}$ for the $\mathrm{CO}_{2}$ emissions savings, between 16 673M€ and 144 012M€ for the investment cost, between $115 \mathrm{TWh}$ and $673 \mathrm{TWh}$ for the imported energy savings, between -205TWh and 66TWh of electricity savings, between -16kt and 84kt of TSP emissions savings, and between 5.6 years and 35.6 years for the payback.

More important than the values found, the study shows that it is possible to narrow down the set of alternatives (EE plans), identifying the possible "best" range of results that can be achieved. The wide variation found among the final sets of preferred solutions confirms the importance of a methodological approach considering multi-objective analysis when building energy efficiency plans, such as the one presented, in order to search for possible unknown solutions and to give guidance and confidence to DMs. 


\section{Acknowledgements}

The authors acknowledge the support of the Portuguese Foundation for Science and Technology (FCT) in the frame of the MIT-Portugal Program by the FCT scholarship SFRH/BD/40006/2007, as well as support by FCT/FEDER Program PEstC/EEI/UI0308/2011.

\section{References}

APREN, 2010. Roteiro Nacional das Energias Renováveis Aplicação da Directiva 2009/28/CE.

Beyer, H.-G., Deb, K., 2001. On self-adaptive features in real-parameter evolutionary algorithms. Evolutionary Computation, IEEE Transactions on DOI - 10.1109/4235.930314 5, 250-270.

Brown, E., Mosey, G., 2008. Analytic Framework for Evaluation of State Energy Efficiency and Renewable Energy Policies with Reference to Stakeholder Drivers ( No. NREL/TP-670-43539). National Renewable Energy Laboratory.

Conselho de Ministros, 2010. Plano Nacional de Acção para as Energias Renováveis.

Deb, K., 2001. Multi-Objective Optimization using Evolutionary Algorithms, Wiley-Interscience Series in Systems and Optimization. John Wiley \& Sons, Chichester.

Deb, K., Pratap, A., Agarwal, S., Meyarivan, T., 2002. A fast and elitist multiobjective genetic algorithm: NSGA-II. Evolutionary Computation, IEEE Transactions on DOI - 10.1109/4235.996017 6, 182-197.

European Parliament, 2006. Directive 2006/32/EC of the European parliament and of the council on energy end use efficiency and energy services and repealing Council Directive 93/76/EEC.

European Union, European Commission, Directorate-General for Energy and Transport, 2005. Doing more with less: Green Paper on energy efficiency. Office for Official Publications of the European Communities, Luxembourg.

Haydt, G., 2011. A Multi-Objective Decision Support Methodology For Developing National Energy Efficiency Plans (PhD Dissertation). Universidade do Porto, Porto.

Haydt, G., Leal, V., Dias, L., 2013. Uncovering the multiple objectives behind national energy efficiency planning. Energy Policy 54, 230-239.

IPCC, 2008. Climate Change 2007: Synthesis Report, Contribution of Working Groups I, II and III to the Fourth Assessment Report of the Intergovernmental Panel on Climate Change. IPCC, Geneva, Switzerland.

Keeney, R.L., 1996. Value-Focused Thinking. Harvard University Press.

McKinsey \& Company, 2009. Pathways to a Low-Carbon Economy - Version 2 of the Global Greenhouse Gas - Abatement Cost Curve.

Ministério de Minas e Energia, 2011. Plano Nacional de Eficiência Energética - PNEf - Premissas e Diretrizes Básicas.

Neves, L.P., Dias, L.C., Antunes, C.H., Martins, A.G., 2009. Structuring an MCDA model using SSM: A case study in energy efficiency. European Journal of Operational Research 199, 834-845.

Resolução do Conselho de Ministros n. ${ }^{\circ}$ 80/2008. DR 97 SÉRIE I, 2008.

Roy, B., 1991. The outranking approach and the foundations of electre methods. Theory and Decision 31, 49-73.

U.S. Department of Energy, U.S. Environmental Protection Agency, 2006. National Action Plan for Energy Efficiency. 